\title{
Effect of Supplementary Cyan Light to Deep Red and Royal Blue Range Wavelengths on the Seedling Period of Iceberg Lettuces
}

\author{
T. Yaşar Katırcıoğlu* Murat Toksavul Mehmet Tabak Çağlar Terzi \\ ARTECS Anadolu R\&D Technology Engineering and Consultancy Inc. Ankara Üniversitesi Teknokent Binası \\ D Blok No:7 06830 Gölbaşı Ankara, Turkey
}

\begin{abstract}
In this article, effect of cyan $(\approx 500 \mathrm{~nm})$ light on the plant growth as a supplementary light source to common deep red $(\approx 660 \mathrm{~nm})$ and royal blue $(\approx 440)$ lights is examined. For this purpose, a 4 -floor shelf was prepared containing Vernalia type iceberg lettuce (Lactuca sativa) seeds. Carbon dioxide content of air, soil moisture, air humidity, environment temperature, water, $\mathrm{pH}$, electrical conductivity, fertilizer and nutrient contents were controlled at desired values; being same for the whole system. Second and third floors were lighted 18 hours a day, with the same photosynthetic photon flux density (PPFD) of $360 \mu \mathrm{mol} \mathrm{m} \mathrm{m}^{-2} \mathrm{~s}^{-1}$. Third floor's lighting was composed of $65 \%$ deep red and 35\% royal blue lights. Second floor's lighting was composed of 55\% deep red, $25 \%$ royal blue and $20 \%$ cyan lights. First floor was lighted with sunlight, in order to make a comparison with natural lighting. Fourth floor contained the necessary control equipment. The experiment lasted for 15 days to analyse only the seedling period. The experiment results showed that, addition of cyan light to conventional red and blue grow lightings allowed the plants to grow $14 \%$ more by stem system. Also, cyan light provided a stronger root development and higher leaf area; which would indicate a higher product yield in the vegetative period.
\end{abstract}

Keywords: Cyan light, artificial lighting, plant growth conditions, seedling period, lettuce, greenhouse efficiency, green light

DOI: $10.7176 / \mathrm{JBAH} / 9-10-11$

Publication date:May $31^{\text {st }} 2019$

\section{Introduction}

Food requirement of the world is highly increasing, with the growing population under favour of new medical technologies and better life conditions. Consequently, healthy and efficient agriculture will be even more important to meet the growing requirement. One of the key instruments to agricultural efficiency and health is to provide accurate lighting to the plants. And, according to researches on plant growth, it seems possible to create an optimal lighting environment using LEDs [1].

McCree [2] examined the light absorptance property of 22 different plants. The mean values of light absorptance of these plants are tabulated as below:

Table 1. Average absorptance of plants

\begin{tabular}{|l|l|}
\hline Light Wavelength & Absorptance \\
\hline $350 \mathrm{~nm}$ & 0.95 \\
\hline $375 \mathrm{~nm}$ & 0.94 \\
\hline $400 \mathrm{~nm}$ & 0.93 \\
\hline $425 \mathrm{~nm}$ & 0.92 \\
\hline $450 \mathrm{~nm}$ & 0.92 \\
\hline $475 \mathrm{~nm}$ & 0.92 \\
\hline $500 \mathrm{~nm}$ & 0.91 \\
\hline $525 \mathrm{~nm}$ & 0.81 \\
\hline $550 \mathrm{~nm}$ & 0.74 \\
\hline $575 \mathrm{~nm}$ & 0.79 \\
\hline $600 \mathrm{~nm}$ & 0.84 \\
\hline $625 \mathrm{~nm}$ & 0.88 \\
\hline $650 \mathrm{~nm}$ & 0.90 \\
\hline $675 \mathrm{~nm}$ & 0.93 \\
\hline $700 \mathrm{~nm}$ & 0.79 \\
\hline $725 \mathrm{~nm}$ & 0.36 \\
\hline $750 \mathrm{~nm}$ & 0.07 \\
\hline
\end{tabular}

Absorptance is not strictly related to decent plant growth, but it gives idea about growth and chlorophyll activity. Near ultraviolet lights which have high absorptance are capable of suppressing plant growth, but they are needed at low levels for normal growth of the plant [3]. It is known that in some conditions, red light alone may provide higher growth and photosynthetic activity; but the shape and the quality of the plant would be weak 
[4]. For ideal plant growth and health, general idea suggests that a combination of royal blue $(\approx 440 \mathrm{~nm})$ and deep red $(\approx 660 \mathrm{~nm})$ lights play the most effective role [5], as chlorophyll-a which is the primary pigment for photosynthesis maximum absorbs light near these wavelengths; while green light band (500-600 nm) has negligible to negative effect [3], [6], [7], [8].

However, several recent studies [9], [10] suggest that addition of green to cyan lights could improve plant growth by stimulating necessary mechanisms when given in lesser amounts with respect to royal blue and deep red lights. Also, green light owing to its very little absorption, is able to penetrate forest canopy and feed lower leaves and backside of the leaves with the help of accessory pigments [11]. In the later sections, this paper will investigate the effect of small amount cyan light $(\approx 500 \mathrm{~nm})$ on plant growth as a supplementary to the deep red $(\approx 660 \mathrm{~nm})$ and royal blue $(\approx 440 \mathrm{~nm})$ lights, with the passion to find optimum lighting conditions for lettuce plant growth.

\section{Experiment}

\subsection{Measurements, equipment and calibration}

In the experiment, a 4-floor shelf was used as main structure that can be seen in Figure 1. Second and third floors were covered with aluminium foils, only leaving the first floor open to sunlight. Visual inspection showed that these floors were completely dark when LEDs were turned off. Fertilizer reinforced peat and perlite soil mixture was used as the ground for plants.

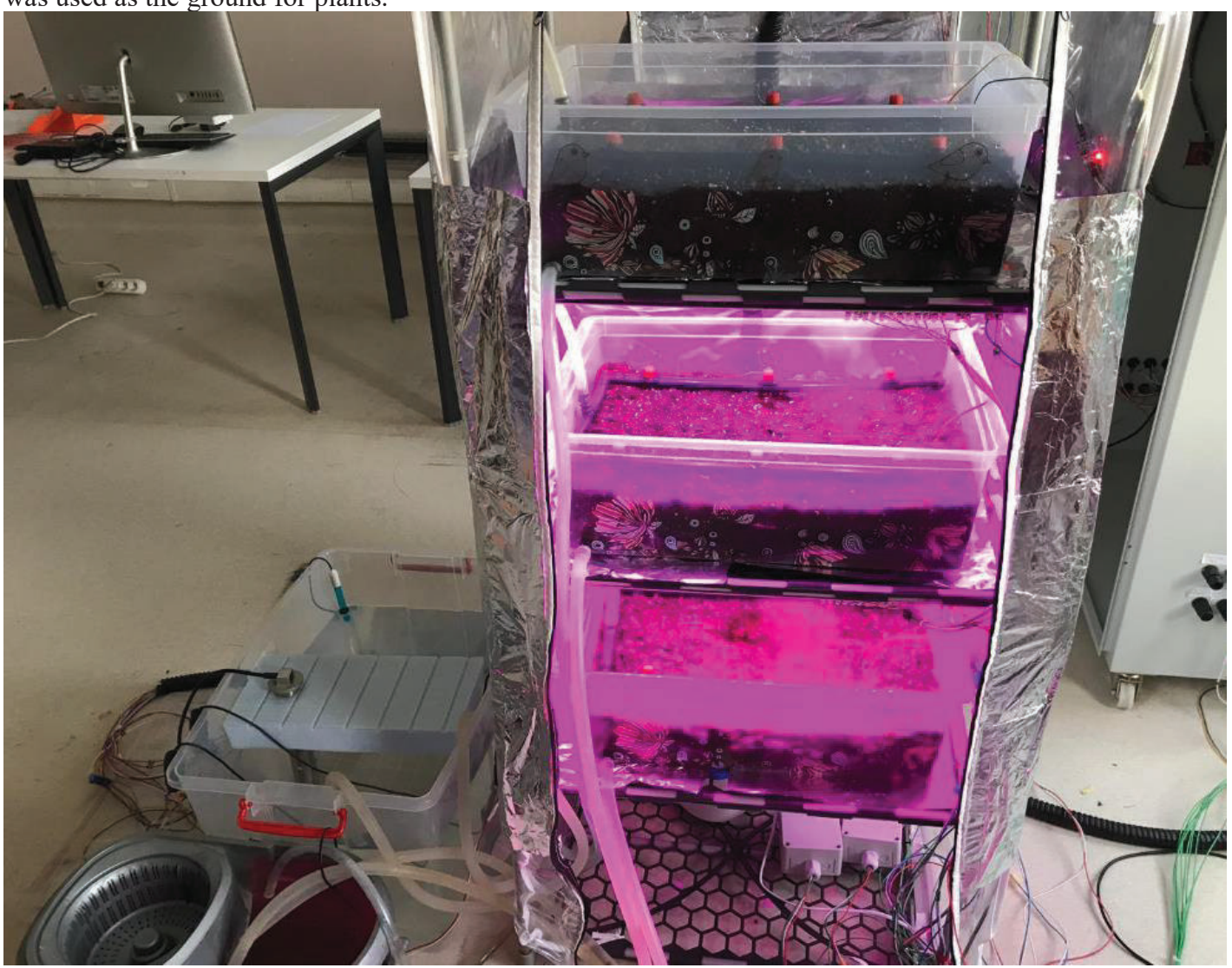

Figure 1. Experimental setup (with external cover half-opened)

12 HC-SR04 acoustic proximity sensors (Figure 2) were used to detect plant elongation in second and third floors. These sensors were compared to each other by measuring same length, and maximum relative difference in measurements found out to be $3 \%$. Plant elongation in first floor was measured via using digital calliper, in order to consider slight plant deflection to window where the sunlight comes. Aside from HC-SR04 measurements, plants on second and third floors were also measured with digital calliper to minimise possible errors.

2 K-type thermocouples (Figure 3) were used on each floor. One to measure the temperature and other as reference. 


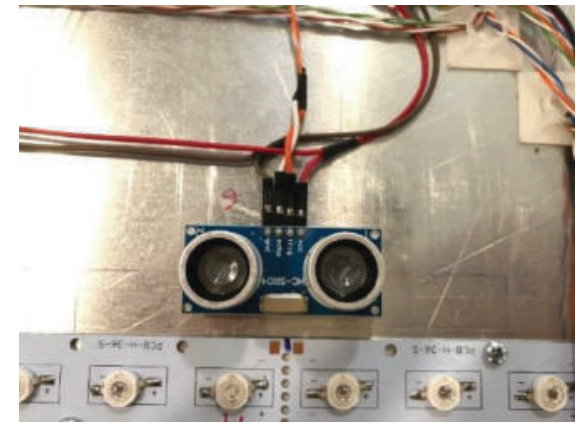

Figure 2. HC-SR04 acoustic proximity sensor

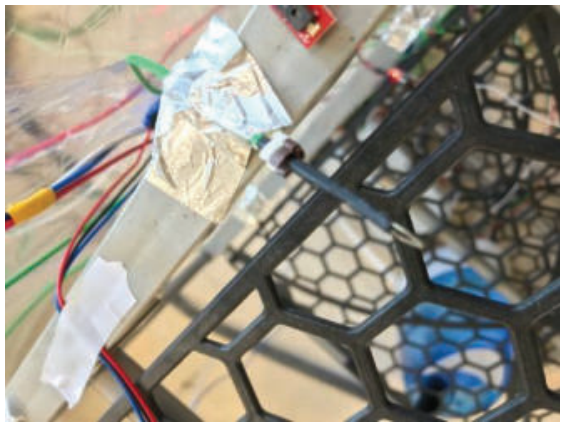

Figure 3. K type thermocouple

Water $\mathrm{pH}$ sensor (Figure 4) was used every 4 hours to measure the $\mathrm{pH}$ of water tank. The sensor was calibrated with interpolation from three different reference liquids at $\mathrm{pH}$ 10.01, 7.01, and 4.01. After the calibration, these liquids were measured as $10.20,7.15$, and $4.04 \mathrm{pH}$ respectively; indicating an approximate accuracy of $98 \%$. Water electrical conductivity was measured with an error less than $2 \%$, which was validated by measuring a known $1400 \mu \mathrm{S} / \mathrm{cm}$ reference around $1420 \mu \mathrm{S} / \mathrm{cm}$.

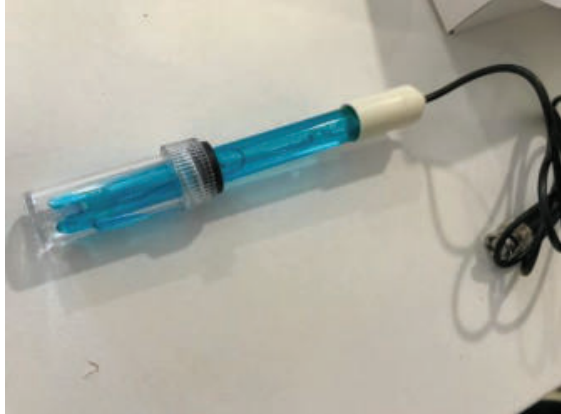

Figure 4. Water $\mathrm{pH}$ sensor

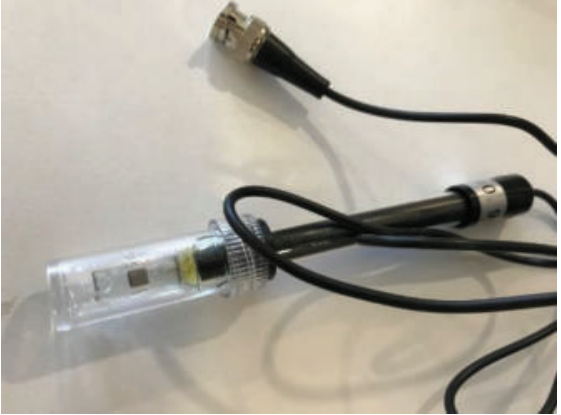

Figure 5. Electrical conductivity sensor

Both air (Figure 6) humidity and soil moisture (Figure 7) were measured with sensors. Soil moisture sensor was problematic after a week due to degradation and seemingly oxidation; thus, they were changed weekly. Real reason for sensor failure is a matter of active research, to later upgrade the sensor or to develop a better one.

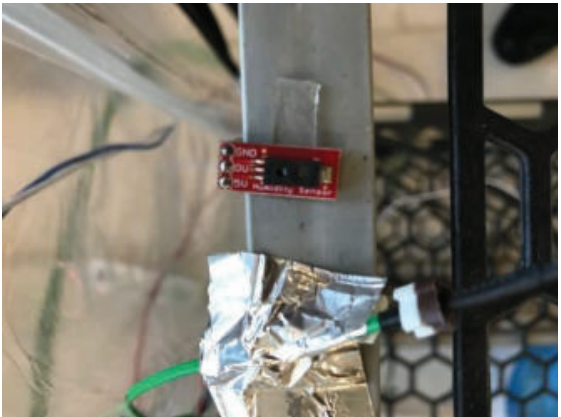

Figure 6. Air humidity sensor

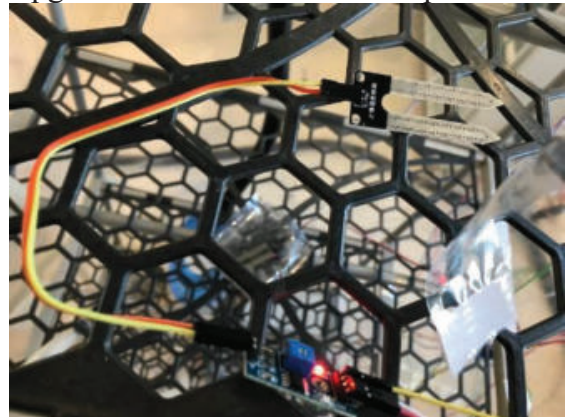

Figure 7. Soil moisture sensor

$\mathrm{CO}_{2}$ content of air (Figure 8) was measured on the fourth floor, together with $\mathrm{O}_{2}$ content (Figure 9). Air circulation provided by fan activity was considered to be enough for homogenous distribution.

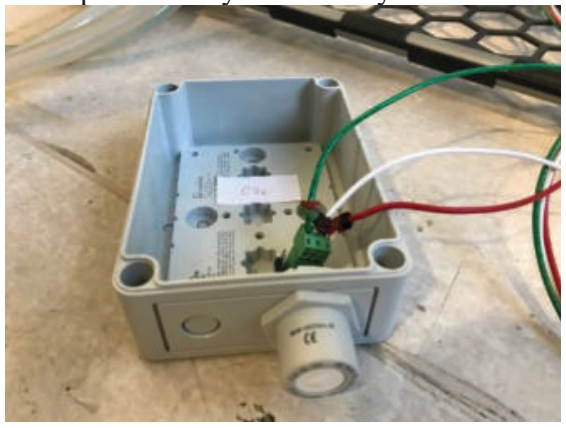

Figure $8 . \mathrm{CO}_{2}$ sensor

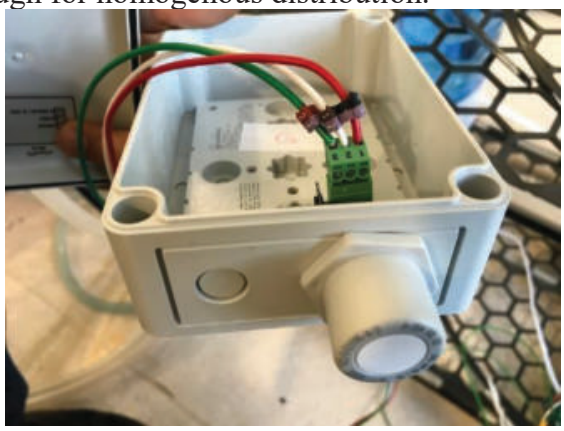

Figure 9. $\mathrm{O}_{2}$ sensor

Rain detector (Figure 10) was used with artificial rains to test the sensor. $24 \mathrm{~V}$ fans (Figure 11) were 
installed on each floor to provide decent air circulation.

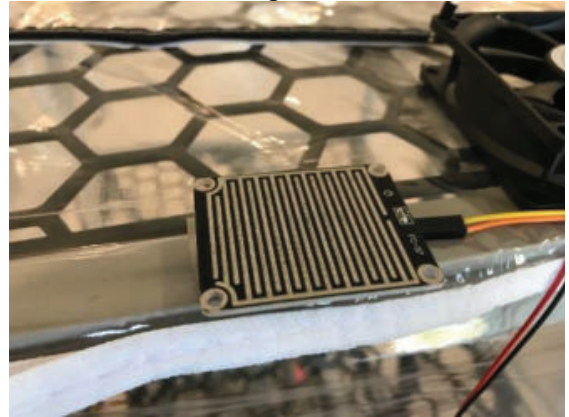

Figure 10. Rain detector

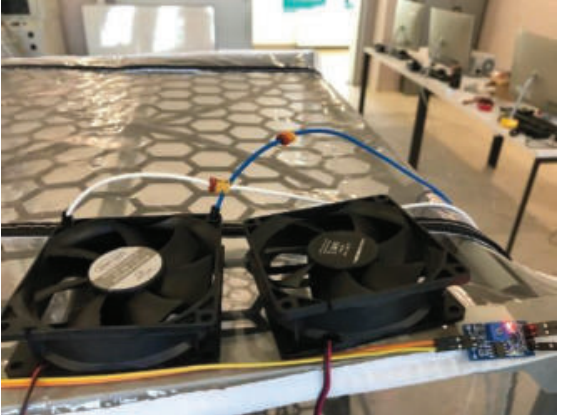

Figure 11. 24 V DC fans

2 aquarium pumps (Figure 12) were used in the water tank, to propel the water through channels of drip irrigation system (Figure 13).

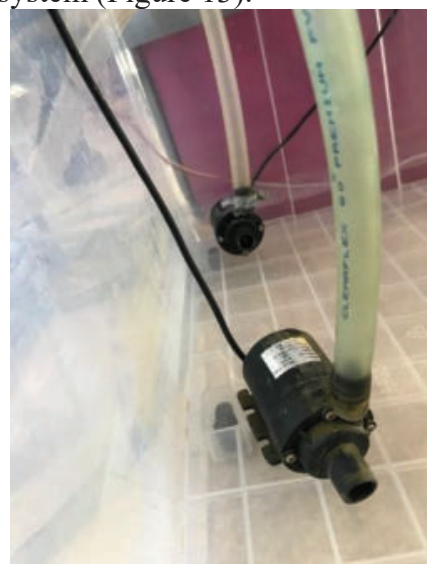

Figure 12. Water pumps

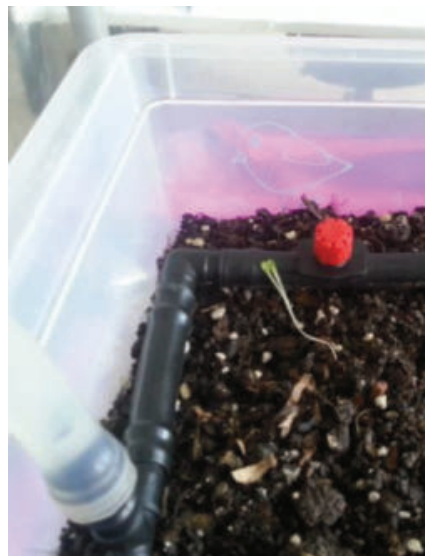

Figure 13. Drip irrigation channels

Water in the water tank was measured with a level sensor (Figure 14). Air humidity was regulated through a humidifier that was canalised into each floor (Figure 15).

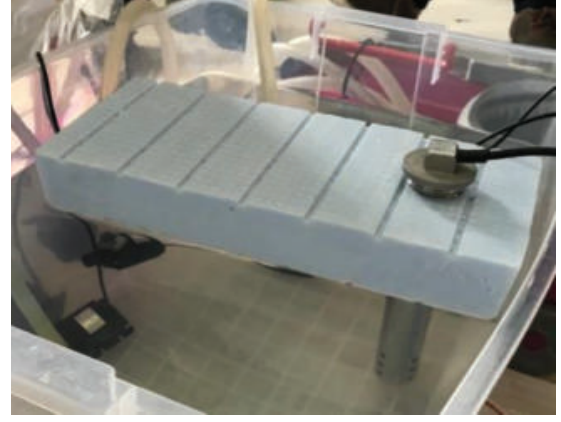

Figure 14. Water level sensor

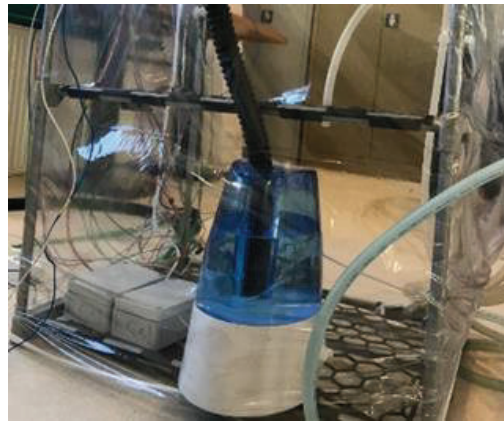

Figure 15. Humidity generator

In order to be controlled, some of the sensors and related equipment were connected to Arduino Mega 2560 (Figure 16). LabView was used as a control software by connecting the Arduino to a PC. 80 pieces of 3 W LEDs with different wavelengths were installed on two aluminium plates (as a cooler) for lighting purpose. These LEDs were set a PPFD of 360 ; and run at $21.19 \mathrm{~V}$ and $20.06 \mathrm{~V}$ for second and third floors, respectively. Resulted amperage was $200 \mathrm{~mA}$ for second, and $193 \mathrm{~mA}$ for third floor. Voltage difference was a consequence of cyan LEDs. The wavelengths and relative power can be seen in Figure 23. 


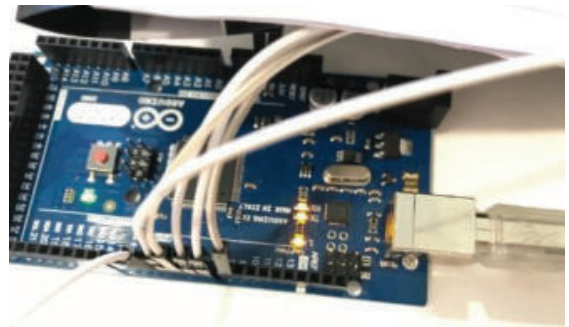

Figure 16. Arduino Mega 2560

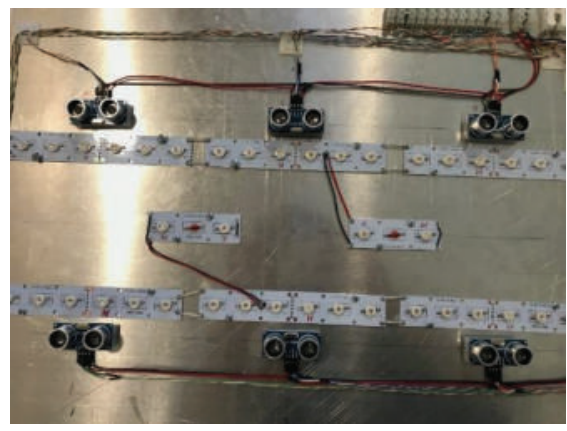

Figure 17. LEDs

Pictures of second and third floors are given in Figure 18, to show the conditions of related environments.
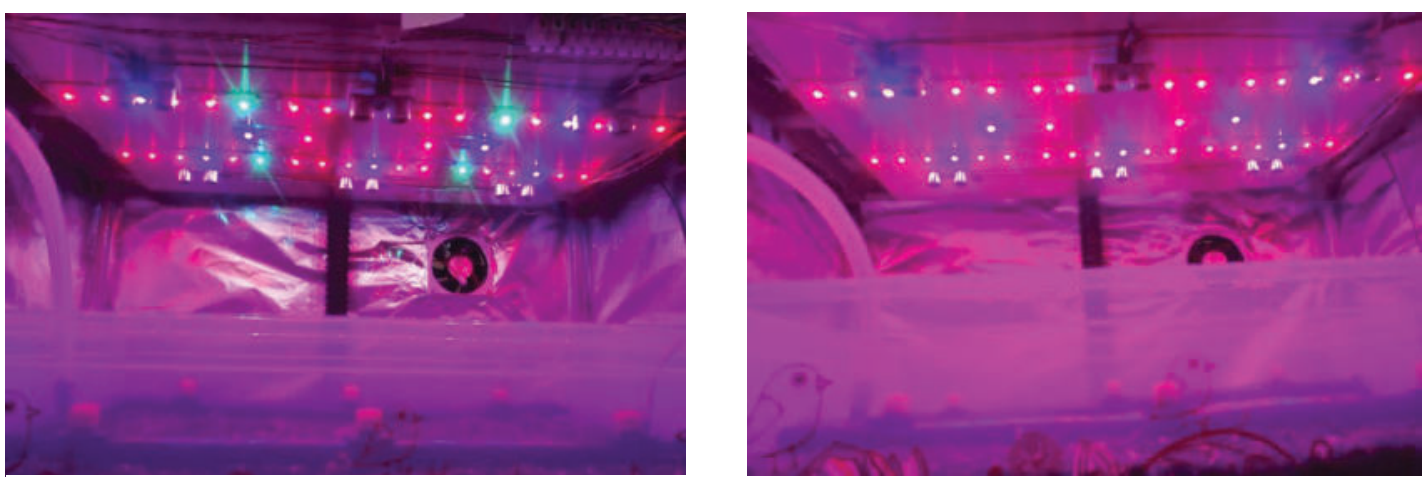

Figure 18. Second (left) and third (right) floors while LEDs are on

\subsection{Seed treatment}

54 Vernalia type iceberg lettuce (Lactuca sativa) seeds were put between wet wool fabrics. Environment temperature was kept between $16-18^{\circ} \mathrm{C}$, as high temperature (usually higher than $25^{\circ} \mathrm{C}$ ) may cause thermodormancy for lettuce seeds [12]. After 3 days, sprouting was observed as can be seen from Figure 19. Then, sprouts were moved to shelf setup and sown $1 \mathrm{~cm}$ [12] down on a pearlite, peat and pebble stone mixture. Pebble stones were used at the bottom of this mixture to ease the diffusion and drainage of water.

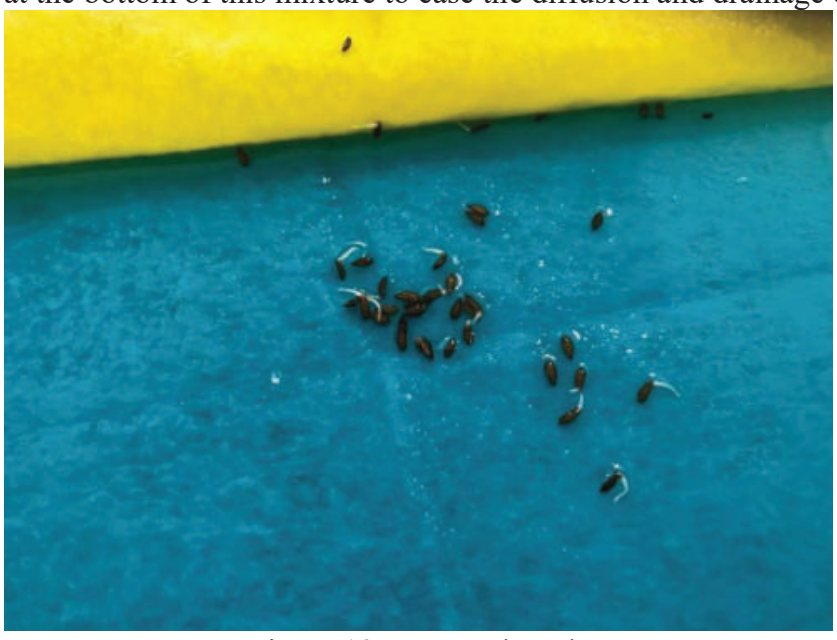

Figure 19. Sprouted seeds

The setup was designed for 18 plants ( 6 spots for grown plants on each floor). Yet, 54 seeds were sown (3 on each spot), which would be later reduced to 18 (1 on each spot). This was done in order to eliminate any possible problems/defects in seeds.

\subsection{Germination and development conditions}

After the sprouts were transplanted to shelves, plant nutrition was added to the water in water tank by using 150 
$\mathrm{ml}$ of a nutrition product named Gentafol $8-8-8$; which contains $8 \%$ urea nitrogen, $8 \%$ water soluble phosphorus pentaoxide, and $8 \%$ water soluble potassium oxide [13]. Since plants would be able to claim oxygen and carbon dioxide from air, and hydrogen from water; nitrogen, phosphorus, potassium, calcium, magnesium and sulphur were considered as required nutrients to be given in water for sufficient growth [14]. $30 \mathrm{~g}$ of dry magnesium sulphate, and $60 \mathrm{ml}$ of wet calcium oxide fertiliser were used to provide lacking nutrients. The amounts were determined from a combination of common usage references [13], [14], [15], product recommendations and live discussions with product specialists. The water tank used had a capacity of 70 litres; and consisted of a combination of mains water (55 litres), drinking water (15 litres), and aforementioned nutrients. Electrical conductivity of the blend measured as $1300 \mu \mathrm{S} / \mathrm{cm}$, which is favourable since ideal range for electrical conductivity for lettuce growth is evaluated as 1100-1500 $\mathrm{S} / \mathrm{cm}$ [9], [12], [16], [17], [18]. pH of the blend was 5.8, which is also in ideal $\mathrm{pH}$ range that is evaluated as 5.5-6.5 [9], [19], [20]. The $\mathrm{pH}$ and electrical conductivity values are important, because an undesired $\mathrm{pH}$ causes availability of elements in water is to be reduced; and an undesired electrical conductivity describes nutrient deficiency or limited uptake of water, depending on its value. $\mathrm{CO}_{2}$ content was monitored and adjusted to be 350-600 ppm in accordance with studies [9], [21], [22], [23]; by means of coal combustion, airing and fans when needed. $410 \mathrm{ppm}$ is the approximate atmospheric $\mathrm{CO}_{2}$ rate of Earth in 2018 [22]. Considering a place with living organisms, 350-600 ppm was realistic; and that was the reason for selected amount although $\mathrm{CO}_{2}$ enrichment in greenhouses can boost production efficiency up to $30 \%$ [21], [23].

Shelf temperature was adjusted to be between $14-22^{\circ} \mathrm{C}$ [12], [23]. It was measured with two type $\mathrm{K}$ thermocouples at each floor; and regulated with the help of electrical heaters, and fans. Although these range of temperatures is considered to be ideal, there are methods consisting different range of temperature applications for short time, such as heat shocking to reach increase crop quality against browning [24].

Both relative air humidity and soil moisture were kept between 50-80\% [23]. Low air humidity may cause smaller and fewer leaves; stomatal resistance (a measure of opposition to transportation from or to stomata of a leaf), decreased $\mathrm{CO}_{2}$ uptake, and decreased photosynthesis levels [25]. Similarly, soil moisture is directly related with water uptake and determines sufficient growth; as maximum growth and marketable yield in plants depends on plant evapotranspiration [26]; which is closely linked with soil moisture. Also, aside from being an unnecessary cost to the grower [27], excessive air humidity may prevent transpiration, and excessive soil moisture may cause several undesired effects [28].

Irrigation was done via pumps and dripping system that propels water from a water tank to plants. Its rate was arranged with respect to sensor readings. Figure 20 shows an example code and average values for some of the measured environmental parameters on first floor for the duration of the experiment.

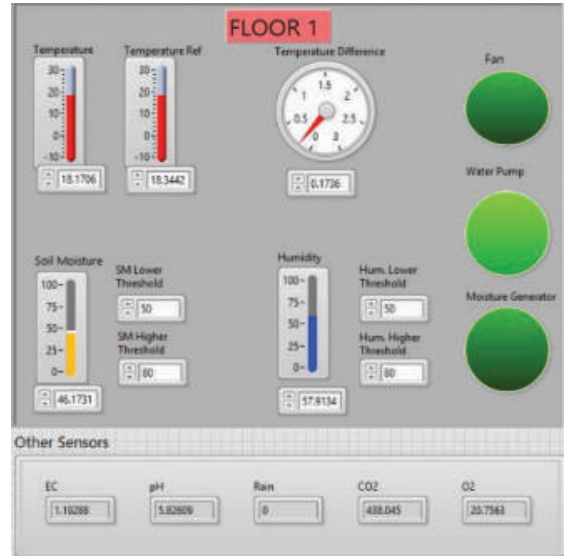

Figure 20. Average measured values of some environmental parameters 


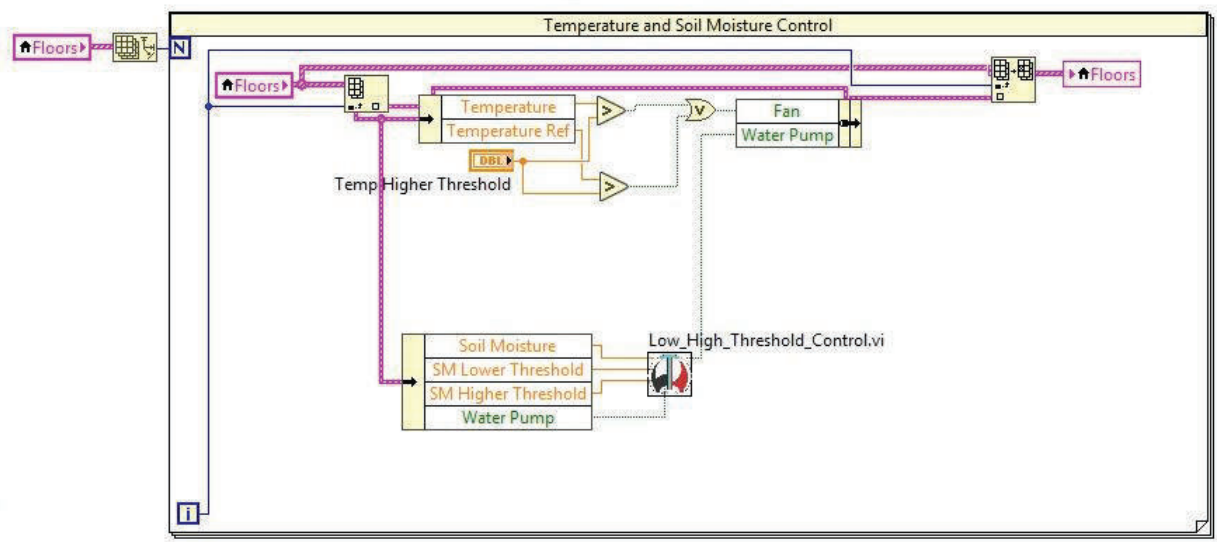

Figure 21. Example code for temperature and soil moisture control in LabView

\subsection{Lighting conditions}

Daily values of photosynthetically active radiation (light between 400-700 nm) for $1 \mathrm{~m}^{2}$ area, with the units of $\mathrm{mol} \cdot \mathrm{m}^{-2}$ per day [29], [30]; varies on outdoors depending on latitude, clouds, time of year, etc. For USA, it is measured as 5-60 $\mathrm{mol} \cdot \mathrm{m}^{-2}$ per day as Figure 22 depicts [31]. Considering geographical position of Mediterranean basin, it seems to be a fair premise that daily photosynthetically active radiation in Mediterranean is in range of 5-60 $\mathrm{mol} \cdot \mathrm{m}^{-2}$. In greenhouses, some portion of the light is absorbed or reflected by the outer cover and structures. Hence, photosynthetically active radiation levels in greenhouses generally ranges from $1-25 \mathrm{~mol} \cdot \mathrm{m}^{-2}$ per day [29], and rarely exceed $30 \mathrm{~mol} \cdot \mathrm{m}^{-2}$ per day [32]; with the help of retractable shade curtains and roofs [29]. In growth chambers, most common values are $10-30 \mathrm{~mol} \cdot \mathrm{m}^{-2}$ per day [33], which can be approximately converted to $115-350 \mu \mathrm{mol} \mathrm{m} \mathrm{m}^{-2} \mathrm{~s}^{-1}$ of PPFD. Also, literature on PPFD effect on plants suggests that, a PPFD above than $330 \mu \mathrm{mol} \mathrm{m} \mathrm{m}^{-2} \mathrm{~s}^{-1}$ is needed to achieve sufficient growth and nutrient value, and depending on the plant type, $330-545 \mu \mathrm{mol} \mathrm{m} \mathrm{m}^{-2} \mathrm{~s}^{-1}$ of PPFD is the most suitable [34]. Thus, although there are studies investigating the effects of different colours of light to lettuce growth by using $150 \mu \mathrm{mol} \mathrm{m} \mathrm{m}^{-2} \mathrm{~s}^{-1}$ of PPFD such as [35], a constant PPFD of $360 \mu \mathrm{mol} \mathrm{m}^{-2} \mathrm{~s}^{-1}$ was arranged in this study to reach maximum difference.
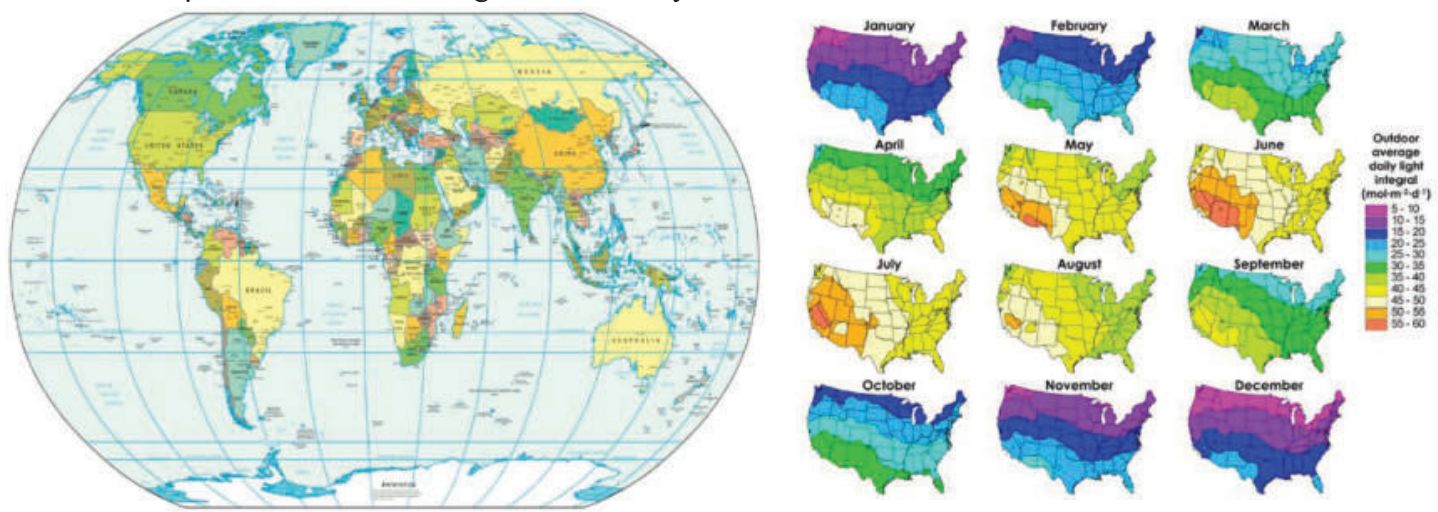

Figure 22. World map and average photosynthetically active radiate on values per day for USA [31], [36]

$\approx 660 \mathrm{~nm}$ power LEDs were used to provide deep red light, $\approx 440 \mathrm{~nm}$ power LEDs were used as royal blue light and $\approx 500 \mathrm{~nm}$ power LEDs were used to provide cyan light. PPFD was set to a constant $360 \mu \mathrm{mol} \mathrm{m}^{-2} \mathrm{~s}^{-1}$ by using filters and controlling power input. The exact wavelengths of mentioned LEDs can be seen in Figure 23, which were measured and validated with an Ocean HR4000 spectrometer.

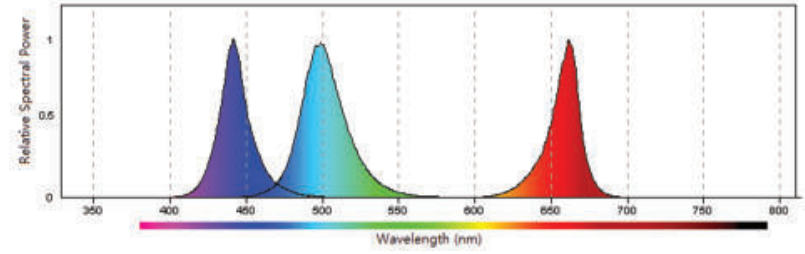

Figure 23. Wavelengths of experimented LEDs

The reason for to select 660 and $440 \mathrm{~nm}$ band was the chlorophyll-a activity, which have the highest mass 
when compared to other photosynthetic pigments in lettuce, as can be seen in Figure 24 [29].

A

口 $\mathrm{Chl} \mathrm{a} \boldsymbol{a}_{\mathrm{Chl} \mathrm{b}}$

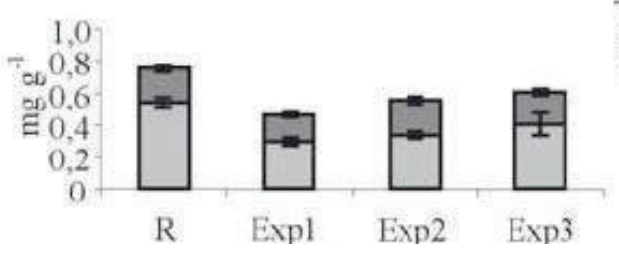

B 0,30

$$
0,25
$$$$
0,20
$$$$
\text { of } 0,15
$$

0,10

0,05

0

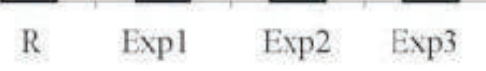

Figure 24. Concentration of photosynthetic pigments chlorophyll a and b (A) and carotenoids (B) in lettuce leaves for 4 different cases [37]

Besides, it should be noted that chlorophyll-b and carotenoids are accessory pigments that are not capable of directly passing the collected energy to photosynthetic pathways, instead they transfer it to chlorophyll-a. Thus, chlorophyll-a activity is the most important parameter when it comes to photosynthesis; and its photon absorption is maximum around $660 \mathrm{~nm}$ and $440 \mathrm{~nm}$, as can be seen from Figure 25 [37].

\section{Photosynthesis Absorption}

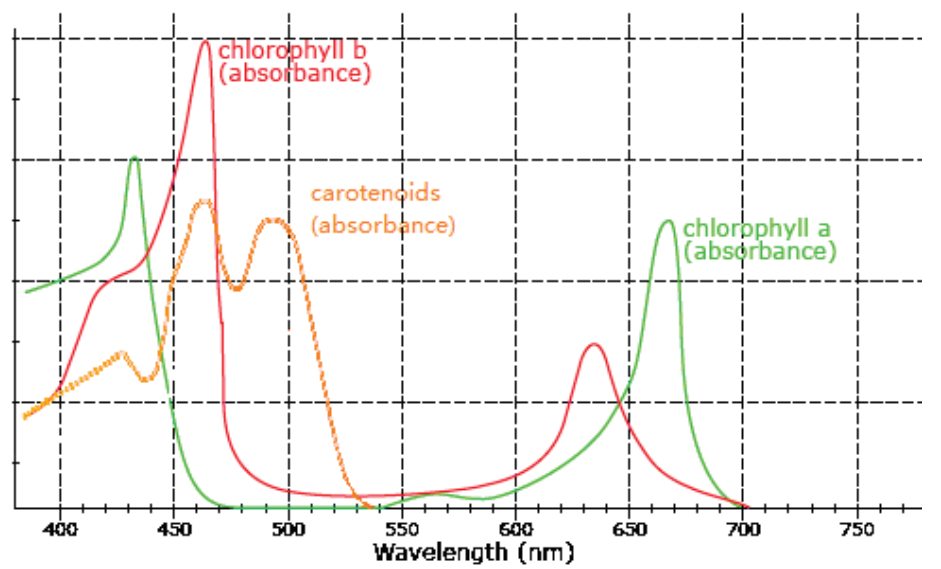

Figure 25: Light absorption of chlorophyll-a, chlorophyll-b, and carotenoids [38]

It is possible to estimate the given energy to lettuces by the lighting system; as the photon energy is described with below formula [39] :

$$
E=\frac{h c}{\lambda}
$$

Where $E$ is photon energy, $h$ is Planck constant, $c$ is speed of the light in vacuum, and $\lambda$ is wavelength of the photon. With this equation and by knowing PPFD and wavelengths, daily given energy is computable since $h$ and $c$ are known constants.

$$
1 \text { day }=24 \times 60 \times 60 \text { seconds }=86400 \text { seconds }
$$

$$
\begin{aligned}
\text { Daily given energy } & =86400 \text { seconds } \times \text { PPFD } \times E=86400 \times 360 \times 10^{-6} \times 6.02 \times 10^{23} \\
\times \frac{\left(6.62607004 \times 10^{-34}\right) \times(299792000)}{\lambda} \text { joules } & =\frac{3.71954}{\lambda} \text { joules }
\end{aligned}
$$

Note that $\lambda$ relation is linear, and LEDs used spread from the peak values in a symmetrical manner; therefore, an average estimation for $\lambda$ can be used for every lighting case.

For second floor (55\% red, $25 \%$ blue, $20 \%$ cyan);

$$
\lambda_{2}=\frac{(55 \times 660)+(25 \times 440)+(20 \times 500)}{100}=573 \mathrm{~nm}
$$

For third floor ( $65 \%$ red, $35 \%$ blue);

$$
\lambda_{3}=\frac{(65 \times 660)+(35 \times 440)}{100}=583 \mathrm{~nm}
$$

Combining equations (5), and (6) with equation (3);

$$
\begin{aligned}
& \text { Daily given energy } y_{2}=\frac{3.71954}{0.000000573} \text { joules }=6491344 \text { joules }=6.49 \mathrm{MJ} \\
& \text { Daily given energy } 3=\frac{3.71954}{0.000000583} \text { joules }=6380000 \text { joules }=6.38 \mathrm{MJ}
\end{aligned}
$$


In another way, sun exerts approximately $1050 \mathrm{~W}$ of power per $\mathrm{m}^{2}$ on Earth's surface on a cloudless summer day afternoon [40]. Since 43\% of this power is in visible spectrum [41], and sun can be considered 4 hours a day of peak power (for a yearly average) [42]; PAR portion of energy given on Earth's surface can be estimated as:

$$
1050 \times 0.43 \times(4 / 24)=75.25 \mathrm{~W} / \mathrm{m}^{2}
$$

Daily given energy $y_{\text {sun-visible }}=75.25 \times 60 \times 60 \times 24$ joules $=6.5 \mathrm{MJ} / \mathrm{m}^{2}$

Results of equations (6), (7) and (8) are similar. Besides considering that equation (9) is calculated for per $\mathrm{m}^{2}$ while each floor of the experimental setup has the approximate area of $0.25 \mathrm{~m}^{2}$, it can be concluded that given energy in the experiment was like a simulation of 16 hours a day sun peak power.

\section{Results}

The experiment continued for 15 days, which considered as seedling period, with the aforementioned germination and development conditions. On each day, elongation readings were taken for the most grown plants of 6 lettuce spots of each floor. Below Table 2 describes these readings and leaf counts.

Table 2. Daily plant elongation amount

\begin{tabular}{|c|c|c|c|c|c|c|c|c|c|c|c|c|c|c|c|c|c|c|}
\hline & \multicolumn{6}{|c|}{ Sunlight $(100 \%)$} & \multicolumn{6}{|c|}{ Red, Blue, Cyan $(55 \%, 25 \%, 20)$} & \multicolumn{6}{|c|}{ Red, Blue $(65 \%, 35 \%)$} \\
\hline Days & \multicolumn{3}{|c|}{ Leaf Count } & \multicolumn{3}{|c|}{$\begin{array}{c}\text { Plant } \\
\text { Length }(\mathrm{mm})\end{array}$} & \multicolumn{3}{|c|}{ Leaf Count } & \multicolumn{3}{|c|}{$\begin{array}{c}\text { Plant } \\
\text { Length }(\mathrm{mm})\end{array}$} & \multicolumn{3}{|c|}{ Leaf Count } & \multicolumn{3}{|c|}{$\begin{array}{c}\text { Plant } \\
\text { Length }(\mathrm{mm})\end{array}$} \\
\hline \multirow{2}{*}{1} & 0 & 0 & 0 & 0 & 0 & 0 & 0 & 0 & 0 & 0 & 0 & 0 & 0 & 0 & 0 & 0 & 0 & 0 \\
\hline & 0 & 0 & 0 & 0 & 0 & 0 & 0 & 0 & 0 & 0 & 0 & 0 & 0 & 0 & 0 & 0 & 0 & 0 \\
\hline \multirow{2}{*}{2} & 0 & 0 & 0 & 1 & 0 & 0 & 0 & 0 & 0 & 0 & 0 & 0 & 0 & $\sigma^{2}$ & 0 & 0 & 0 & 1 \\
\hline & 0 & 0 & 0 & 0 & 2 & 1 & 0 & 0 & 0 & 0 & 1 & 0 & 0 & 0 & 0 & 0 & 0 & 0 \\
\hline \multirow{2}{*}{3} & 0 & 0 & 0 & 15 & 0 & 0 & 2 & 2 & 2 & 4 & 3 & 3 & 0 & 2 & 2 & 0 & 2 & 4 \\
\hline & 0 & 0 & 0 & 16 & 11 & 15 & 2 & 2 & 2 & 2 & 4 & 5 & 2 & 0 & 2 & 2 & 1 & 2 \\
\hline \multirow{2}{*}{4} & 0 & 0 & 0 & 26 & 0 & 0 & 2 & 2 & 2 & 8 & 8 & 9 & 2 & 2 & 2 & 4 & 8 & 11 \\
\hline & 0 & 0 & 0 & 25 & 23 & 24 & 2 & 2 & 2 & 7 & 9 & 11 & 2 & 2 & 2 & 10 & 6 & 5 \\
\hline \multirow{2}{*}{5} & 0 & 0 & 0 & 32 & 0 & 0 & 2 & 2 & 2 & 12 & 10 & 14 & 2 & 2 & 2 & 13 & 16 & 18 \\
\hline & 0 & 0 & 0 & 41 & 38 & 36 & 2 & 2 & 2 & 10 & 13 & 20 & 3 & 2 & 2 & 16 & 13 & 13 \\
\hline \multirow{2}{*}{6} & 2 & 0 & 0 & 37 & 0 & 0 & 2 & 2 & 3 & 12 & 11 & 16 & 2 & 2 & 2 & 16 & 17 & 20 \\
\hline & 2 & 0 & 0 & 46 & 41 & 38 & 2 & 2 & 2 & 14 & 15 & 22 & 3 & 2 & 2 & 17 & 15 & 14 \\
\hline \multirow{2}{*}{7} & 2 & 0 & 0 & 41 & 0 & 0 & 2 & 2 & 3 & 15 & 13 & 17 & 2 & 2 & 3 & 21 & 17 & 21 \\
\hline & 2 & 2 & 2 & 50 & 44 & 39 & 2 & 3 & 2 & 14 & 19 & 26 & 3 & 2 & 2 & 18 & 18 & 18 \\
\hline \multirow{2}{*}{8} & 2 & 0 & 0 & 42 & 0 & 0 & 2 & 3 & 3 & 19 & 16 & 18 & 3 & 3 & 3 & 21 & 19 & 21 \\
\hline & 2 & 2 & 2 & 51 & 49 & 45 & 3 & 3 & 3 & 16 & 21 & 27 & 3 & 3 & 2 & 23 & 19 & 18 \\
\hline \multirow{2}{*}{9} & 2 & 0 & 0 & 52 & 0 & 0 & 2 & 3 & 4 & 22 & 20 & 24 & 3 & 3 & 3 & 22 & 20 & 25 \\
\hline & 2 & 2 & 2 & 45 & 48 & 51 & 3 & 3 & 3 & 14 & 22 & 30 & 3 & 3 & 3 & 20 & 21 & 18 \\
\hline \multirow{2}{*}{10} & 2 & 0 & 0 & 52 & 0 & 0 & 2 & 3 & 4 & 27 & 24 & 33 & 3 & 3 & 4 & 35 & 28 & 30 \\
\hline & 2 & 2 & 2 & 51 & 45 & 52 & 3 & 3 & 3 & 26 & 29 & 42 & 3 & 3 & 3 & 29 & 28 & 24 \\
\hline \multirow{2}{*}{11} & 2 & 0 & 0 & 52 & 0 & 0 & 3 & 3 & 4 & 36 & 32 & 33 & 4 & 3 & 4 & 33 & 32 & 33 \\
\hline & 2 & 2 & 2 & 46 & 46 & 53 & 3 & 3 & 3 & 33 & 42 & 46 & 3 & 3 & 3 & 32 & 36 & 31 \\
\hline \multirow{2}{*}{12} & 2 & 0 & 0 & 47 & 0 & 0 & 3 & 4 & 4 & 35 & 34 & 35 & 4 & 3 & 4 & 34 & 32 & 33 \\
\hline & 2 & 2 & 2 & 40 & 51 & 53 & 3 & 4 & 3 & 34 & 41 & 45 & 3 & 4 & 3 & 35 & 36 & 34 \\
\hline \multirow{2}{*}{13} & 2 & 0 & 0 & 21 & 0 & 0 & 4 & 4 & 4 & 37 & 35 & 37 & 4 & 4 & 4 & 33 & 33 & 35 \\
\hline & 2 & 2 & 2 & 35 & 59 & 52 & 4 & 4 & 4 & 35 & 42 & 41 & 4 & 4 & 3 & 36 & 36 & 36 \\
\hline \multirow{2}{*}{14} & 2 & 0 & 0 & 19 & 0 & 0 & 5 & 5 & 4 & 38 & 34 & 40 & 4 & 4 & 4 & 34 & 37 & 39 \\
\hline & 2 & 2 & 2 & 34 & 61 & 53 & 4 & 5 & 4 & 38 & 43 & 40 & 4 & 4 & 3 & 39 & 38 & 38 \\
\hline \multirow{2}{*}{15} & 0 & 0 & 0 & 0 & 0 & 0 & 5 & 5 & 5 & 43 & 39 & 40 & 4 & 5 & 4 & 35 & 35 & 40 \\
\hline & 3 & 2 & 2 & 24 & 64 & 53 & 4 & 5 & 4 & 37 & 49 & 44 & 5 & 5 & 4 & 37 & 37 & 37 \\
\hline
\end{tabular}

Note that plants are living organisms and may bend, twist, fall or die. These effects cause measurement error and sometimes real contraction in plant length. On average, cyan addition to conventional lighting boosted the elongation $14 \%$ on $15^{\text {th }}$ day. Calculation is as done as: 


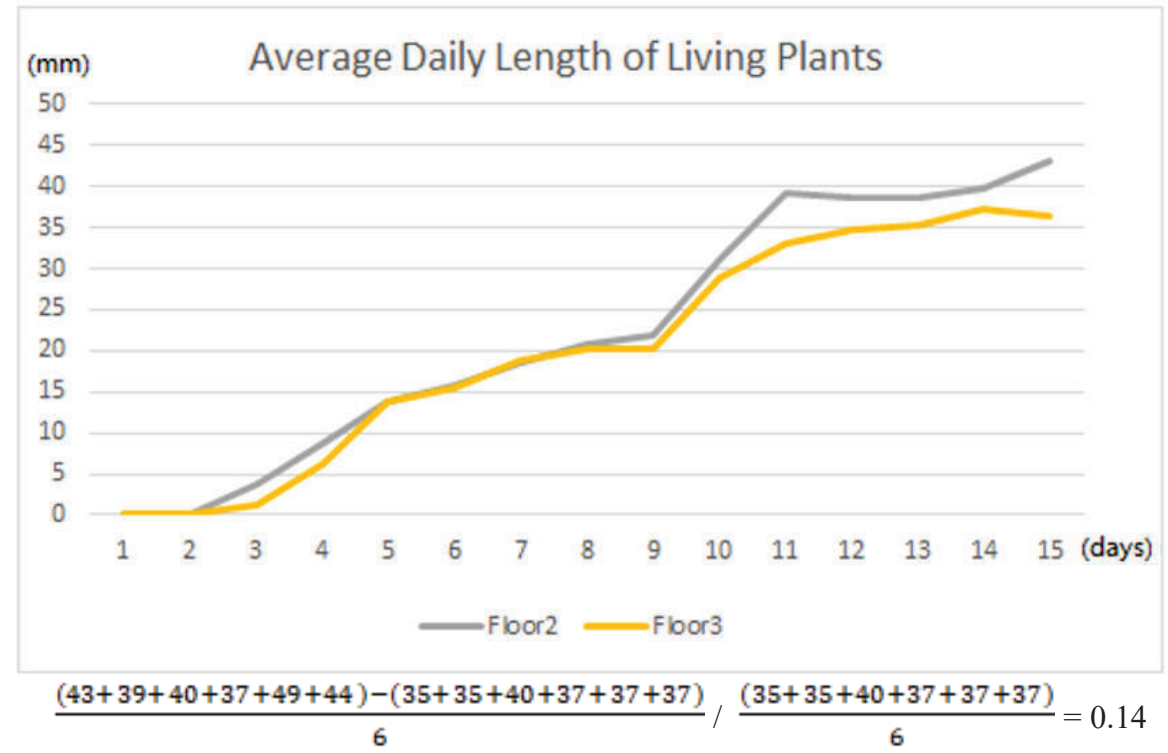

Figure 26. Average daily length of living plants for each floor for 15 days

Figure 26 graphically represents plant length in Table 2, for better interpretation. Elongation in the first floor is not included, since they starved for light and did not actualise a healthy development. Figure 27 shows the condition of plants on $8^{\text {th }}$ day. Visual growth difference is noticeable in the first look.

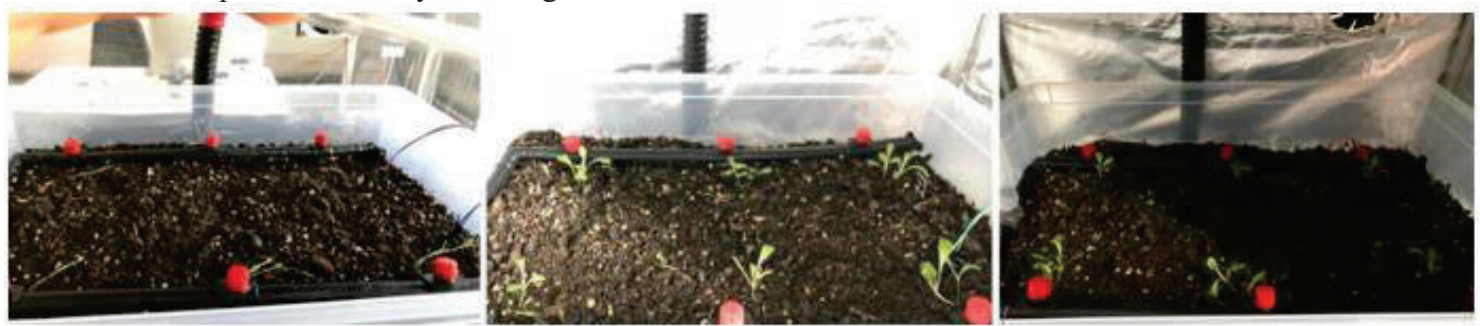

Figure 27. Plants on $8^{\text {th }}$ day (first, second and third floors respectively)

1 plant from each floor was extracted on $15^{\text {th }}$ day to make a m ore detailed analysis. shows a picture of these extracted samples. A more detailed, ultimate comparison of setups for $15^{\text {th }}$ day is made and tabulated in Table 3

Table 3. Detailed comparison of setups on $15^{\text {th }}$ day

\begin{tabular}{|l|l|l|l|}
\hline & $\begin{array}{l}\text { Sunlight } \\
(\mathbf{1 0 0 \% )}\end{array}$ & $\begin{array}{l}\text { Red-Blue- } \\
\text { Cyan (55\%- } \\
\text { 25\%-20) }\end{array}$ & $\begin{array}{l}\text { Red-Blue } \\
\mathbf{6 5 \% -} \\
\mathbf{3 5 \%}\end{array}$ \\
\hline $\begin{array}{l}\text { Number of } \\
\text { leaves }\end{array}$ & 2 & 4 & 4 \\
\hline $\begin{array}{l}\text { Shoot } \\
\text { length (mm) }\end{array}$ & 24.05 & 48.85 & 40.56 \\
\hline $\begin{array}{l}\text { Root length } \\
\text { (mm) }\end{array}$ & 17.15 & 24.31 & 9.78 \\
\hline $\begin{array}{l}\text { Stem } \\
\text { thickness } \\
\text { (mm) }\end{array}$ & 0.41 & 0.65 & 0.59 \\
\hline $\begin{array}{l}\text { Leaf area } \\
\text { (mm }{ }^{2} \text {, one- } \\
\text { sided) }\end{array}$ & 20 & 280 & 155 \\
\hline
\end{tabular}

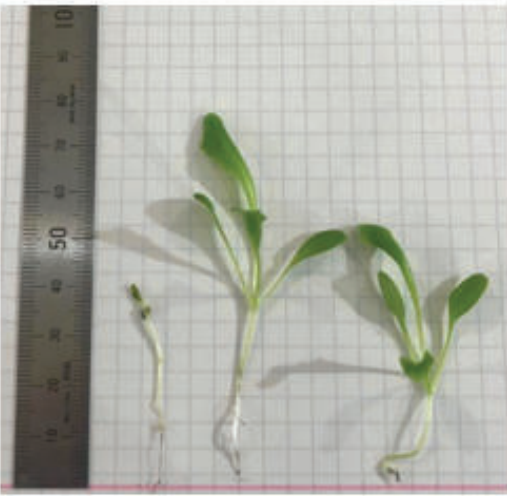

Figure 28. Samples from the first (left), second (middle) and third

\section{Discussion}

Shoot length in second floor and third floor setups were observed much higher than sunlight setup in Figure 28; but as can be confirmed from Table 2, daily plant elongation for sunlight setup was dramatically higher than 
second and third setups for the first week. Main reason for this is evaluated to be that the plants were facing a light deficiency, and hence try to grow towards to window where the sunlight comes instead of producing leaves. The experiment was done in a building and only one side was open to sunlight. There is no point of leaves if there is no light to process. Leaf count that can be seen from Table 3, also supports this idea. In the last week, all of the plants on first floor seem weak and half of them stopped growing.

Number of leaves is related with the useable light, and in both second and third floor setups have approximately equal number of leaves on average. However, leaf area of second floor's plants were significantly larger than the rest. This would provide better photosynthetic capability; hence, a faster growth rate in vegetative period. It is unreasonable to compare the sunlight setup with respect to number of leaves, unless grown on outside. Still, but smaller difference would be expected in that case.

Stem thickness is higher in second floor plants. As stem is the carrier of the plant, leaves and fruits/vegetables to be produced; thicker stem is an indicator of higher product yield. Root length is confusing, as third floor plants seemingly failed to develop a strong and extensive root. The mechanisms of root development should be studied in later researches.

One of the possible reasons of the results, is that near green lights including cyan have relatively low absorptance by plants; and this provides light to penetrate inside the higher leaves of the plant to slowly being absorbed by backside of higher leaves and by lower leaves, feeding them for photosynthesis. There is an ideal wavelength and relative amount to this phenomenon, and it seems near cyan wavelengths and \%20 relative amount according to results.

Another reason may be that cyan light put carotenoids into use and get absorbed by them [43]. This should increase photosynthesis efficiency in the plant somehow, since idling pigments were started to work. But mechanisms stimulated by cyan range light in the seedling period requires further studies to be properly understood.

The results are promoting cyan light, and artificial lighting; but its cost must be also considered. For this purpose, energy spend for LEDs can be used to calculate the operational cost of artificial lighting:

- For second floor;

$21.19 \mathrm{~V}, 200 \mathrm{~mA}$ and 18 hours a day working time would indicate $0.076 \mathrm{kWh}$ energy usage. Taking current electricity price in Turkey as $0.714 \mathrm{TRY} / \mathrm{kWh}$ [44], cost of electricity would be estimated as $0.054 \mathrm{TL} /$ day. Note that average price of a lettuce in Ankara Turkey is 2.31 TRY [45]; and 1 Turkish lira (TRY) equals to 0.15 euro (EUR) [46] or 0.17 dollar (USD) [47].

- $\quad$ For third floor;

$20.06 \mathrm{~V}, 193 \mathrm{~mA}$ and 18 hours a day working time would imply $0.070 \mathrm{kWh}$ of energy used. From here, electricity cost can be found as $0.050 \mathrm{TRY} /$ day.

As lighting price calculations were done on a system for 6 lettuces, added cost per lettuce can be found as 0.054 TRY / $6=0.009$ TRY for second floor. Thus, in order to compensate the cost of artificial lighting, each lettuce head should approximately be sold $0.009 \times 35=0.315$ TRY (harvesting on $35^{\text {th }}$ day [23]) more expensive. With respect to price of a lettuce, and considering lettuces cover much less space while in seedling period than given in experiment; possible improvement on elongation rate and production efficiency regarding sunlight setup outweighs the cost and artificial lighting usage with cyan light added is evaluated as highly profitable.

\section{Conclusion}

In conclusion, cyan light added setup consistently grew much better than the setup with only red and blue lights. According to elongation results (Table 2), there happened a $14 \%$ improvement on $15^{\text {th }}$ day. Also, as can be seen in Table 3, both stem and root systems are healthier in setup with cyan light.

The results of this study, as expected, are parallel to aforementioned [6], [8], [9], [10] findings of studies about green range lights, even though conventional industrial knowledge [38] suggests that red and blue light bands are the best for greenhouse applications. Cyan light addition in a specific amount can boost the growth and production efficiency in seedling period with respect to only red and blue light usage in greenhouses.

Growth difference in vegetative period will be a topic on later studies. It is planned to experiment the effect of cyan light addition in vegetative period by cross changing half of the plants in second and third floors. Conventionally, red light known as responsible for plant growth and blue light known as responsible for fruit production. But this studies' results suggest that cyan light has a considerable effect in plant growth. Which mechanisms in plant it stimulates can also be a research topic for later studies.

Since it is near impossible for humans to analyse effects of every wavelength in variable relative powers, there is a free field and necessity in the area of plant growth which can be answered with an artificial intelligence software. An extensively developed artificial intelligence with the goal of analysing effect of every parameter is an active research topic in AR\&TeCS; and its adaptation to find perfect blend of wavelengths. 


\section{References}

[1] Went, Frits W. (1958). "Experimental Control of Plant Growth." Journal of the American Pharmaceutical Association (Scientific Ed.), vol. 47, no. 4, p. 307., doi:10.1002/jps.3030470431.

[2] McCree, K. J. (1971). "The Action Spectrum, Absorptance and Quantum Yield of Photosynthesis in Crop Plants." Agricultural Meteorology, vol. 9, pp. 191-216., doi:10.1016/0002-1571(71)90022-7.

[3] Klein, R. M., et al. (1965). "Effects of Near Ultraviolet and Green Radiations on Plant Growth." Plant Physiology, vol. 40, no. 5, pp. 903-906., doi:10.1104/pp.40.5.903.

[4] Saito, Yuta, et al. (2010). "The Effect of Light Quality on Growth of Lettuce." IFAC Proceedings Volumes, vol. 43, no. 26, pp. 294-298., doi:10.3182/20101206-3-jp-3009.00052.

[5] Matsuda, Ryo, et al. (2004). "Photosynthetic Characteristics of Rice Leaves Grown under Red Light with or without Supplemental Blue Light." Plant and Cell Physiology, vol. 45, no. 12, pp. 1870-1874., doi:10.1093/pcp/pch203.

[6] Folta, K. M., and S. A. Maruhnich. (2007). "Green Light: a Signal to Slow down or Stop." Journal of Experimental Botany, vol. 58, no. 12, pp. 3099-3111., doi:10.1093/jxb/erm130.

[7] Dougher, Tracy A. O., and Bruce Bugbee. (2007). "Evidence for Yellow Light Suppression of Lettuce Growth." Photochemistry and Photobiology, vol. 73, no. 2, pp. 208-212., doi:10.1562/00318655(2001)0730208efylso2.0.co2.

[8] Wang, Yihai, and Kevin M. Folta. (2013). "Contributions of Green Light to Plant Growth and Development." American Journal of Botany, vol. 100, no. 1, pp. 70-78., doi:10.3732/ajb.1200354.

[9] Chang, Chung-Liang, and Kuang-Pi Chang. (2014). "The Growth Response of Leaf Lettuce at Different Stages to Multiple Wavelength-Band Light-Emitting Diode Lighting." Scientia Horticulturae, vol. 179, pp. 78-84., doi:10.1016/j.scienta.2014.09.013.

[10] Gioia D. Massa, Hyeon-Hye Kim, et al. (2008). "Plant Productivity in Response to LED Lighting." HortScience, vol. 43 (7), hortsci.ashspublications.org/content/43/7/1951.full.pdf html.

[11] Wollaeger, Heidi, et al. (2018) “Green Light: Is It Important for Plant Growth?” MSU Extension, www.canr.msu.edu/news/green_light_is_it_important_for_plant_growth.

[12] Starke Ayres Co. (2014). "Lettuce Production Guideline.” Lettuce-Production-Guideline-2014, Starke Ayres Co., www.starkeayres.co.za/com_variety_docs/Lettuce-Production-Guideline-2014.pdf.

[13] Genta Inc. GENTAFOL | $\overline{8}-8-8 \mid$ NPK NUTRITION SOLUTION | Genta Tarim, gentatarim.com/en/urun/gentafol-npk-8-8-8-npk-gubre-cozeltisi/. Retrieved: 21.03.2019

[14](2019). "The Beginner's Guide to Mixing Hydroponic Nutrients." Upstart University, university.upstartfarmers.com/blog/mixing-hydroponic-nutrients.

[15] Almeida, Pollyana Hammerschmidt, et al. (2016). "Increase in Lettuce (Lactuca Sativa L.) Production by Foliar Calcium Application.” Australian Journal of Basic and Applied Sciences, vol. 10, no. 1016, pp. 161167.

www.researchgate.net/publication/315477634_Increase_in_lettuce_Lactuca_sativa_L_production_by_foliar calcium_application.

[16] Smith, Harley. (2016). "Master the Art of Measuring EC." Maximum Yield - Your Modern Growing Resource, www.maximumyield.com/master-the-art-of-measuring-ec/2/1425.

[17] "Just 4 Growers: Global Garden Community." Just For Growers, www.just4growers.com/stream/hydroponic-growing-techniques/nutrient-solution-management-tips-forgrowing-lettuce-using-nutrient-film-technique-(nft).aspx. Retrieved: 21.03.2019

[18] "EC and Plant Growth." HortiCentar, horticentar.mk/en/ec-and-plant-growth/. Retrieved: 21.03.2019

[19] "Vegetable Requirements." Ph/ TDS/PPM Levels for Vegetables, Home Hydro Systems, www.homehydrosystems.com/ph_tds_ppm/ph_vegetables_page.html. Retrieved: 21.03.2019

[20] "Plant PH/EC/PPM." Online Hydroponics Shop, hydroponic.co.za/hydroponics-quickstart/plant-phecppm/. Retrieved: 21.03.2019

[21] Becker, Christine, and Hans-Peter Kläring. (2016). "CO2 Enrichment Can Produce High Red Leaf Lettuce Yield While Increasing Most Flavonoid Glycoside and Some Caffeic Acid Derivative Concentrations." Food Chemistry, vol. 199, pp. 736-745., doi:10.1016/j.foodchem.2015.12.059.

[22] "Earth's CO2." CO2.Earth, www.co2.earth/. Retrieved: 22.03.2019

[23] Brechner, Melissa, et al. (2013). "Hydroponic Lettuce Handbook." Cornell Controlled Environment Agriculture, cea.cals.cornell.edu/attachments/Cornell CEA Lettuce Handbook .pdf.

[24] Saltveit, Mikal E. "Heat-Shock and Fresh Cut Lettuce. (1998)." Perishables Handling Quarterly, no. 95, pp. 5-6., www.researchgate.net/publication/242405677_Heat-Shock_and_Fresh_Cut_Lettuce.

[25] Tibbitts, Theodore W., and G. B. Bottenberg. (1976). "Growth of Lettuce (Lactuca Sativa) under Controlled Humidity Levels." Journal of the American Society for Horticultural Science, vol. 101, no. 1, www.researchgate.net/publication/233860952_Growth_of_lettuce_Lactuca_sativa_under_controlled_humid 
ity levels.

[26] Kuslu, Yasemin, et al. (2016). "Yield and Quality Responses of Drip-Irrigated Spinach to Different Irrigation Quantities in a Semi-Arid Region with a High Altitude." Journal of Central European Agriculture, vol. 17, no. 3, pp. 763-777., doi:10.5513/jcea01/17.3.1774.

[27] Liu, Zhigang, and Qinchao Xu. (2018) "Precision Irrigation Scheduling Using ECH2O Moisture Sensors for Lettuce Cultivated in a Soilless Substrate Culture." Water, vol. 10, no. 5, p. 549., doi:10.3390/w10050549.

[28](2015). "Excessive And Irregular Irrigation Has The Following Effects." Biology Discussion, www.biologydiscussion.com/articles/excessive-and-irregular-irrigation-has-the-following-effects/2403.

[29] Faust, James E., et al. (2005). "The Effect of Daily Light Integral on Bedding Plant Growth and Flowering" HortScience, vol. $40 \quad$ (7) American Society for Horticultural Science, journals.ashs.org/hortsci/view/journals/hortsci/40/3/article-p645.xml.

[30] Bula, R.j., et al. (1991). "Light-Emitting Diodes as a Radiation Source for Plants." HortScience, vol. 26 , no. 2, pp. 203-205., doi:10.21273/hortsci.26.2.203.

[31] Torres, Ariana P., and Roberto G. Lopez. (2011). "Measuring Daily Light Integral in a Greenhouse." Commercial Greenhouse Production, Department of Horticulture and Landscape Architecture, Purdue University, www.extension.purdue.edu/extmedia/ho/ho-238-w.pdf.

[32] Poorter, Hendrik, et al. (2016). "Pampered inside, Pestered Outside? Differences and Similarities between Plants Growing in Controlled Conditions and in the Field." New Phytologist, vol. 212, no. 4, pp. 838-855., doi:10.1111/nph.14243.

[33]Lopez, Roberto G., and Erik S. Runkle. (2008). "Photosynthetic Daily Light Integral during Propagation Influences Rooting and Growth of Cuttings and Subsequent Development of New Guinea Impatiens and Petunia." HortScience, vol. 43, no. 7, pp. 2052-2059., doi:10.21273/hortsci.43.7.2052.

[34] Samuoliene, Giedre, et al. (2014). "Light-Emitting Diodes: a Tool for Growth and Metabolism Handle." 14th International Symposium on the Science and Technology of Lighting. Institute of Horticulture, Lithuanian Research Centre for Agriculture and Forestry.

[35] Han, Tao, et al. (2017). "Improving 'Color Rendering' of LED Lighting for the Growth of Lettuce." Scientific Reports, vol. 7, no. 1, doi:10.1038/srep45944.

[36] "World Map - Political.” Geology, geology.com/world/world-map.shtml. Retrieved: 22.03.2019

[37] Viršile, Akvilè, Pinho, Paulo, et al. (2007). "Effect of short-wavelength light on lettuce growth and nutritional quality" Sodininkystè ir daržininkystè, vol .26, pp 157-165.

[38] Albosauce.com. "Video: Red Light vs Blue Light:How Spectrums Effect Plant Growth." Red \& Blue LED Grow Lights, But Where's the Green??? -AlboPepper.com, albopepper.com/red-blue-LED-grow-lightswith-no-green-spectrum.php. Retrieved: 19.03.2019.

[39]"Energy of Photon". Photovoltaic Education Network, pveducation.org. Retrieved: 22.03.2019 web.archive.org/web/20160712123152/http://pveducation.org/pvcdrom/2-properties-sunlight/energyphoton.

[40] "Terrestrial Spectra." Introduction to Solar Radiation, Newport, www.newport.com/t/introduction-to-solarradiation. Retrieved: 22.03.2019

[41] "Solar." Illumination, Innovation, Transformation, www.immunolight.com/applications/solar/.

[42] Baker, Alyssa. (2019) "How to Calculate Your Peak Sun-Hours." Solar Power Authority, www.solarpowerauthority.com/how-to-calculate-your-peak-sun-hours/.

[43] Farabee, M. J. (2007). "What Is Photosynthesis?" Photosynthesis, www2.estrellamountain.edu/faculty/farabee/BIOBK/BioBookPS.html.

[44] EnCazip Team. (2019) “2019 Electricity Prices.” EnCazip, encazip.com/elektrik-fiyatlari.

[45] "Product Price Details." Republic of Turkey Ministry of Customs and Trade Marketplace Registration System, www.hal.gov.tr/Sayfalar/FiyatDetaylari.aspx. (the price is for 15.04 .2019 , iceberg is on page $9,6^{\text {th }}$ row)

[46] "TRY EUR | Turkish Lira Euro." Investing.com UK, uk.investing.com/currencies/try-eur. Retrieved: 15.04.2019

[47] “TRY USD | Turkish Lira Dollar.” Investing.com UK, uk.investing.com/currencies/try-usd. Retrieved: 15.04.2019 